\title{
Fractographic Assessment and FEM Energy Analysis of the Penetrability of a 6061-T Aluminum Ballistic Panel by a Fragment Simulating Projectile
}

\author{
Aleksander Nieoczym ${ }^{1 *}$, Kazimierz Drozd ${ }^{1}$ \\ 1 Mechanical Engineering Faculty, Lublin University of Technology, ul. Nadbystrzycka 36, 20-618 Lublin, Poland \\ * Corresponding author's email: a.nieoczym@pollub.pl
}

\begin{abstract}
In aviation and light vehicles, aluminum plates are often used instead of heavy shields as ballistic shields. The standard shrapnel was used in the analysis due to the fact that under hazardous conditions, the shrapnel destruction occurs more often than directly with a bullet. Analyses were performed in which the initial velocity and the angle of impact were the variables. The material of the aluminum plate (ballistic shield) with a thickness of $1 \mathrm{~mm}$ was divided into three-dimensional C3D4 tetragonal elements. The calculations were performed using the Johnson-Cook model for the impact at an adjustable velocity from $25 \mathrm{~m} / \mathrm{s}$ to $55 \mathrm{~m} / \mathrm{s}$ every $10 \mathrm{~m} / \mathrm{s}$ and impact angle set between $0^{\circ}$ and $45^{\circ}$ in increments of $15^{\circ}$. Stress maps that allow observation of the plate degradation areas were placed in the plate. It was found that the penetration of the ballistic panel by the fragment under simulated conditions occurs at the initial velocity of this fragment greater than $25 \mathrm{~m} / \mathrm{s}$. The fragment simulating a projectile, hitting at a velocity of $35 \mathrm{~m} / \mathrm{s}$ at an angle of not more than $15^{\circ}$ perforates this panel. At an impact velocity of $45 \mathrm{~m} / \mathrm{s}$, perforation occurred at an impact angle of up to $30^{\circ}$. A further increase of the fragment' velocity of impact on the plate resulted in its perforation even at the greatest impact angle.
\end{abstract}

Keywords: standard projectile fragment, ballistic panel, 6061-T aluminum, FEM

\section{INTRODUCTION}

Ballistic panels made of aluminum alloys are used in the applications for which the main design criterion is a maximum strength to weight ratio. Aluminum alloys allow reducing the weight of the protective structure by up to about $25 \%$, compared to steel with a similar ballistic performance [1]. Currently, thin metal ballistic panels are widely used in ground transportation and aviation [2]. The most important parameter of a ballistic panel is its penetrability by projectiles. The effectiveness of penetrating the panel depends on the velocity of the projectile, its trajectory and the shape of the nose. A projectile with a spherical nose is the least effective penetrator, compared to ogive-nosed and flat-nosed projectiles [3, 4]. Similar conclusions were made in [5], where the highest ballistic limit was observed for spherical-nosed projectiles and the lowest for hemispherical- and flat-nosed impactors. Penetrability was described mathematically as a function of decrease in projectile velocity and energy dissipation [6]. At low impact velocities, global energy was the highest for flat-nosed projectiles. The results of the ballistic tests were used as input for the numerical tests of penetration of $1 \mathrm{~mm}$ thick aluminum plates with flat-nosed and hemispherical-nosed projectiles [3, 7, 8 ]. A FEM adaptive mesh was employed, which accurately reflects the real conditions of penetration of a plate with a hemispherical-nosed projectile. The investigations were extended to include thin spherical aluminum plates [9]. It was shown that the ballistic resistance grew with increasing plate diameter.

The impact energy absorption characteristics were also investigated in [10], where aluminum target plates arranged in various configurations 
were impacted with hemispherical-nosed projectiles. The structures that offered the most effective ballistic protection were (in order of effectiveness) a monolithic panel, followed by two plates stack together, and finally a multi-layered plate with an air gap between the sheets. Similar issues were discussed in [11] in reference to a system comprising light dual plates - the so-called Whipple shield. The main goal of that study was to estimate the energy loss during the perforation of the outer plate (the bumper). The authors determined what geometrical parameters of the inner plate would allow stopping debris or maximally reduce projectile velocity during penetration.

In articles [7, 12], the changes in absorbed impact energy were studied as a function of impact angle. Numerical simulations were carried out in which projectiles with different nose shapes impacted a thin aluminum plate at angles in the range of $0 \div 45^{\circ}$. The highest energy absorption values were recorded for ogive-nosed projectiles, and they increased along with the impact angle. The values recorded were used to calculate the penetration energy and energy dissipated by the plate for different configurations of plate thickness, plate height and projectile velocity. An assessment of the ballistic resistance of aluminum plates subjected to high velocity impact by a cylinder imitating a projectile is given in [13]. The penetrability conditions were not investigated; the impact energies were compared against the impact area and panel thickness. The 2024-T3 aluminum plates were found to provide critical ballistic velocities comparable to GLARE 4A fiber-metal laminates of the same thickness.

The problems related to the testing of penetration of aluminum alloy plates are discussed fairly frequently in the literature, but the main focus of these discussions is the perforation with a projectile, while the debris hazard is usually ignored [14]. However, experimental research and observations from numerous armed conflicts clearly show that debris poses a greater threat than undamaged projectiles. Statistically speaking, targets are more often destroyed when they are impacted by projectile fragments than when they are struck by an unbroken projectile $[15,16]$.

\section{Numerical model of a target and a projectile fragment}

FEM numerical simulations were conducted to investigate the effect of the impact angle and velocity of a standard projectile fragment on the penetrability of a $1 \mathrm{~mm}$ thick aluminum plate. The analysis was carried out in the Abaqus software suite. A solid model of the fragment was made according to the standards - Fig. $1[17,18]$.

The standard projectile fragment was assigned the following properties:

- Material - steel E360

- Young's modulus - $210000 \mathrm{MPa}$,

- Poisson's ratio $v=0.3$.

- Yield strength $\mathrm{R}_{\mathrm{e}}=360 \mathrm{MPa}$,

- plastic deformation corresponding to the level of yield strength was assumed to be equal 0 ,

- ultimate tensile strength $\mathrm{Rm}=510 \mathrm{MPa}$, with the corresponding plastic elongation of the sample at $15 \%$ break.

- material density $7860 \mathrm{~kg} / \mathrm{m}^{3}$.

The material properties and geometrical dimensions assigned in the standards allowed us to obtain a fragment with a standardized weight of $1.1 \mathrm{~g}$.

Material properties were assigned to the ballistic plate:

- material: aluminum 6061-T6,
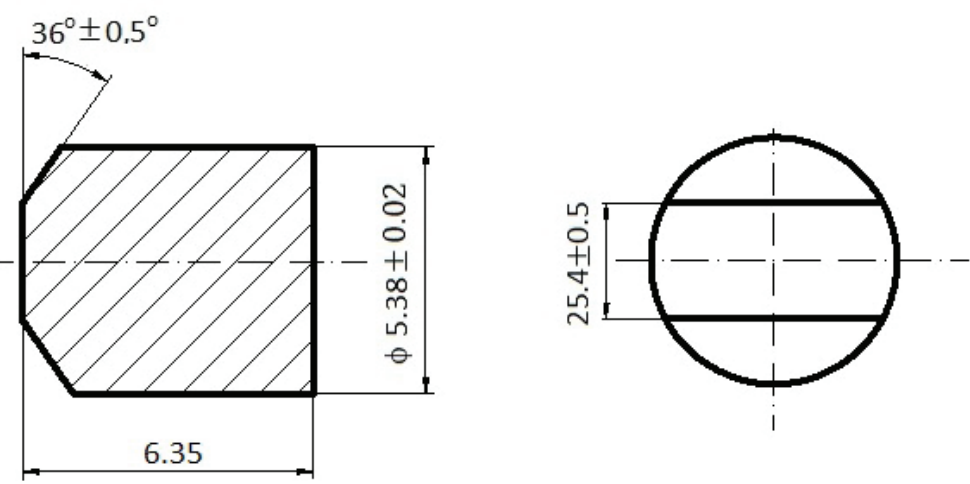

Fig. 1. Standard projectile fragment type 1 according to PN-V-87000:2011 [17, 18] 
- material density $2700 \mathrm{~kg} / \mathrm{m}^{3}$,

- Young's modulus $70000 \mathrm{MPa}$.

- Poisson's ratio $v=0.33$.

The models were discretized using a finite element mesh of tetragonal solid (C3D4) elements with a linear shape function; global mesh density was $0.75 \mathrm{~mm}$.

The behavior of the plate material was described using the Johnson-Cook constitutive material model, which represents the behavior of materials subjected to dynamic loads. Material constant values $\mathrm{A}, \mathrm{B}, \mathrm{n}$ were determined using statistical methods whereas $\mathrm{C}$ and $\mathrm{m}$ were determined on the basis of dynamic tests. The plate had the following parameters: $\mathrm{A}=324.1$, $\mathrm{B}=113.8, \mathrm{n}=0.42, \mathrm{C}=0.002, \mathrm{~m}=1.34$, melting point $\mathrm{T}_{\mathrm{p}}=926^{\circ} \mathrm{C}$, initial temperature $\mathrm{T}=293.2^{\circ} \mathrm{C}$ $[12,19,20]$.

Under the initial conditions of the analysis, the ductile damage criterion was adopted, which allows visualizing the damage of discretized finite elements subjected to impact. A damage map was created for the ballistic panel only. The ductile damage criterion could not be used for the fragment, because it cannot be applied to the elements with assigned weight. A time step of $0.001 \mathrm{~s}$ was used for the calculations. Figure 2 shows the investigated configuration of the fragment simulating projectile and the ballistic panel.

The experiments were conducted for the following graded series of impact angles: $0^{\circ}, 15^{\circ}$, $30^{\circ}$ and $45^{\circ}$. The simulation was performed at initial velocities $\mathrm{v}=25,35,45$, and $55 \mathrm{~m} / \mathrm{s}$. The maps of reduced stresses generated in the ballistic panel are shown in Figs. 3-6.

The largest deformation was observed at impact velocity $\mathrm{v}=25 \mathrm{~m} / \mathrm{s}$ for a fragment fired at angles of $0^{\circ}$ and $30^{\circ}$, with local stresses of up to $350 \mathrm{MPa}$. When the fragment was launched at angles of $15^{\circ}$ and $45^{\circ}$, plastic deformation of the plate was small and the integrity of the structure was disrupted only slightly.

At the impact velocity of $35 \mathrm{~m} / \mathrm{s}$ (Fig. 4), local stresses of up to $400 \mathrm{MPa}$ were observed. As the angle of incidence increased, the level of the plate deformation decreased. When the fragment impacted the target at angles of $0^{\circ}$ and $15^{\circ}$, it heavily disrupted its internal structure, breaking its continuity, as the ultimate strength of the material was exceeded. Smaller deformations, but similar in form, occurred at the impact angle of $30^{\circ}$. In the case of the largest angle tested, impact only led to the deflection of the plate.

At impact velocity $\mathrm{v}=45 \mathrm{~m} / \mathrm{s}$ and impact angles of $0^{\circ}, 15^{\circ}$ and $30^{\circ}$, the fragment perforated the material completely, with bent petals observed on the exit side of the penetration channel. A projectile fired at the impact angle of $45^{\circ}$ only disrupted the structure of the material with some spalling on the projectile exit side (Fig. 5).

The projectile which impacted the plate at $55 \mathrm{~m} / \mathrm{s}$ (Fig. 6), perforated it completely in all analyzed cases. The velocity of the penetrator was so high that parts of the material were torn away from the plate. When fired at the angle of $45^{\circ}$, the impacting fragment not only bent the material in the place where it passed through the plate, but also twisted a significant part of the plate around the perforation hole

The speed of $25 \mathrm{~m} / \mathrm{s}$ was insufficient for the projectile to perforate the thin aluminum plate and so it ricocheted off the plate on the side of the impact. At this velocity, as the impact angle increased, the fragment lost less and less velocity. This situation is shown in Fig. 7. A fragment moving at the angle of $45^{\circ}$ at $25 \mathrm{~m} / \mathrm{s}$ ricocheted off the plate. At higher velocities, the fragment perforated the ballistic panel partially or completely.
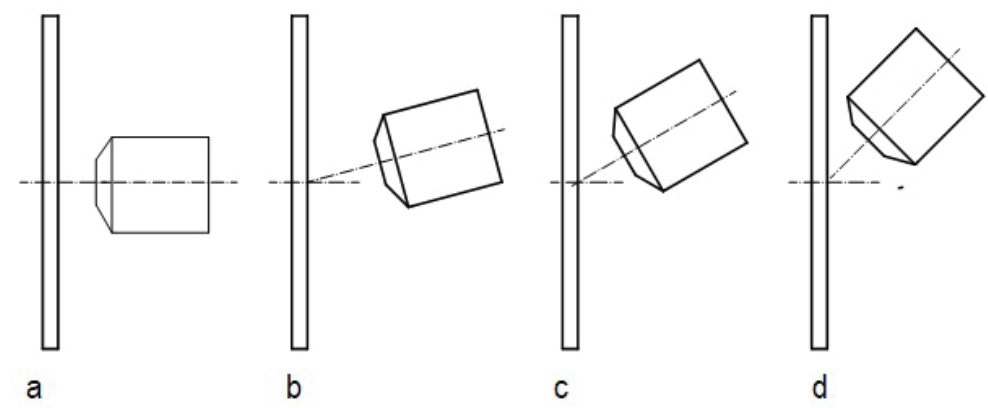

Fig. 2. Assembling the numerical model - hitting the fragment on the ballistic plate at an angle of: a) $0^{\circ}$, b) $15^{\circ}$, c) $30^{\circ}$ and d) $45^{\circ}$ 

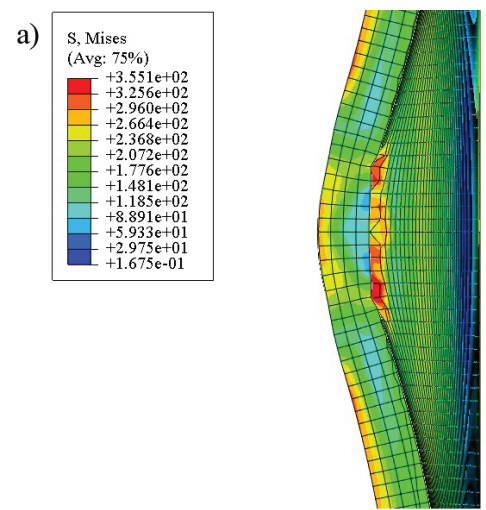

b)
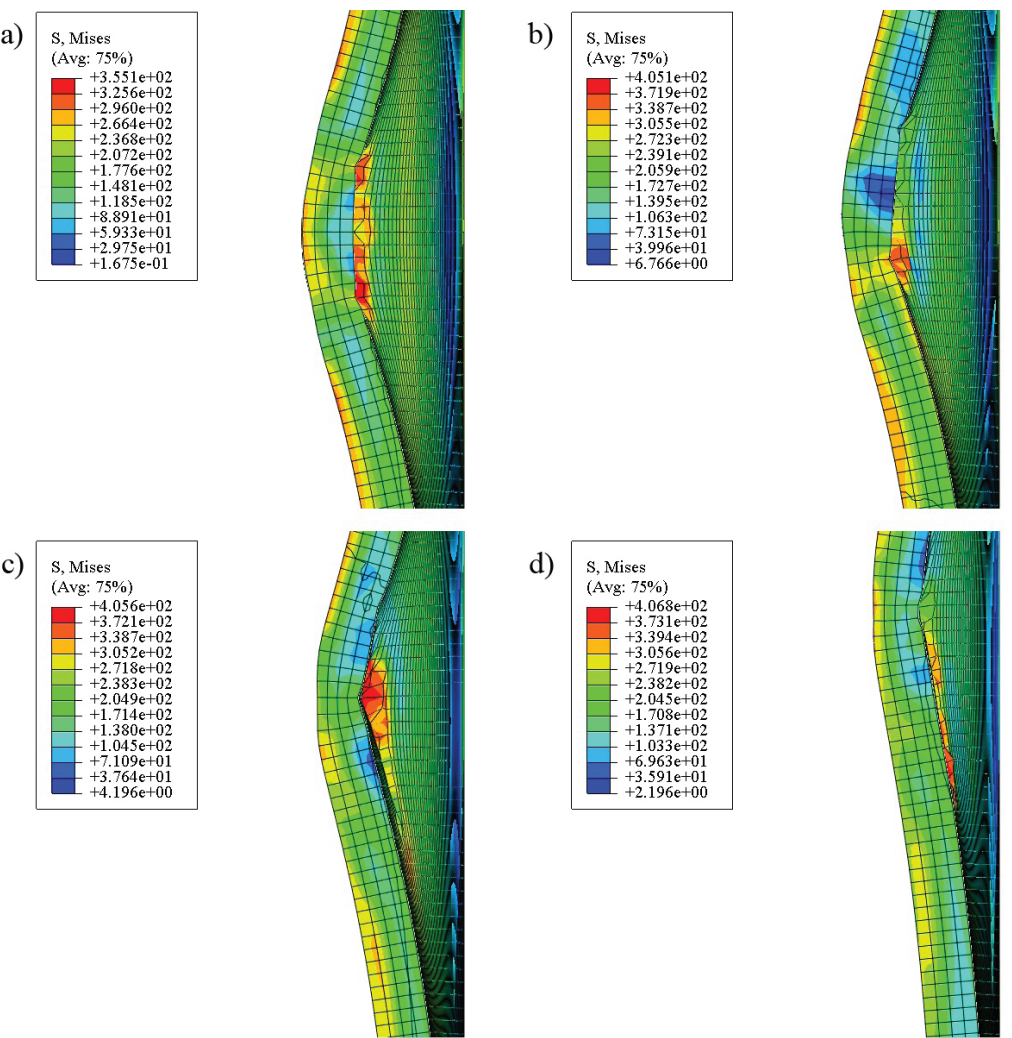

Fig. 3. Maps of reduced stresses in a ballistic plate at the impact of the fragment at the initial velocity $\mathrm{v}=25 \mathrm{~m} / \mathrm{s}$ and the angle of impact: a) $0^{\circ}$, b) $15^{\circ}$, c) $30^{\circ}$ and d) $45^{\circ}$

a)
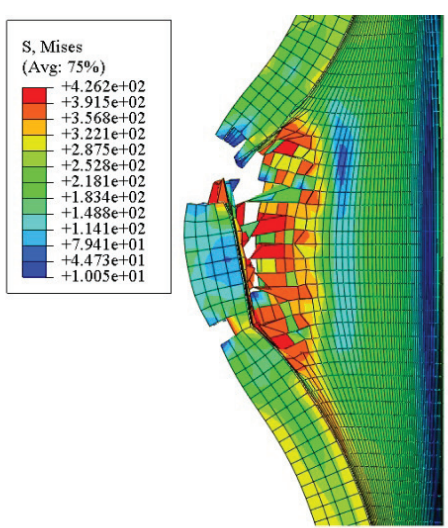

c)

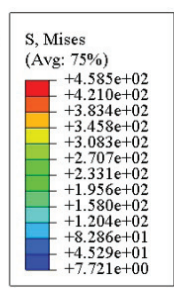

b)
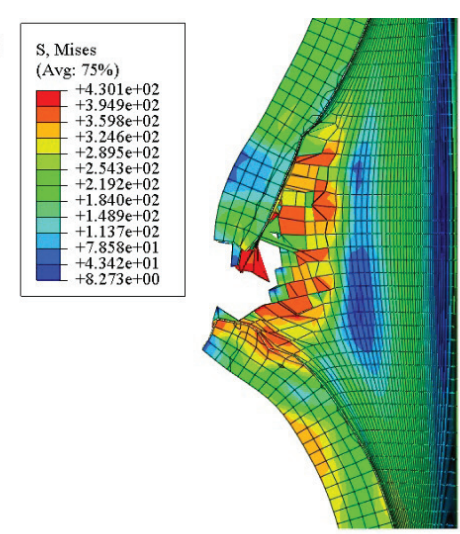

d)

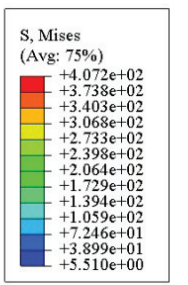

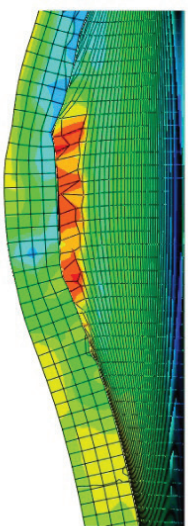

Fig. 4. Maps of reduced stresses in ballistic plate at the impact of the fragment at the initial velocity $\mathrm{v}=35 \mathrm{~m} / \mathrm{s}$ and the angle of impact: a) $0^{\circ}$, b) $15^{\circ}$, c) $30^{\circ}$ and d) $45^{\circ}$ 

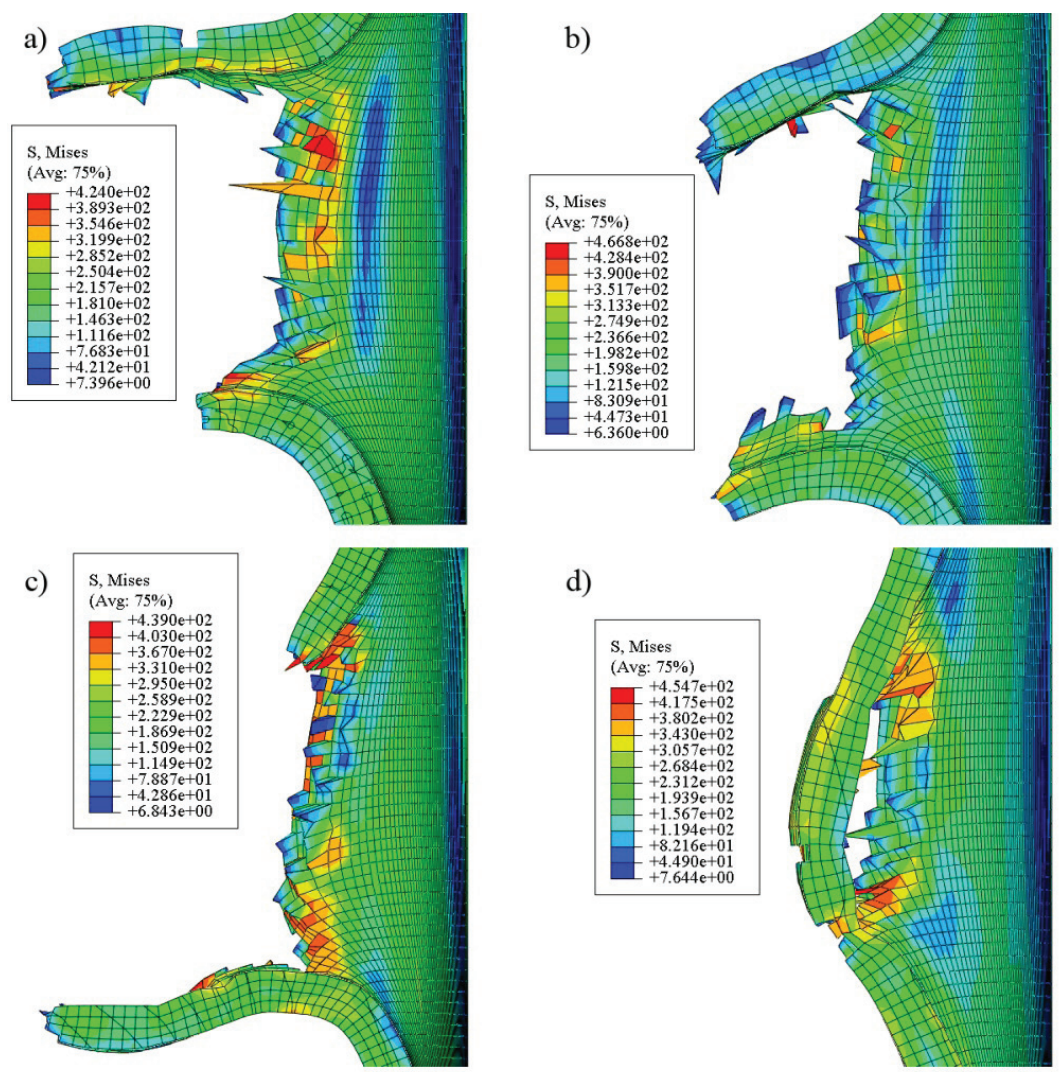

Fig. 5. Maps of reduced stresses in a ballistic plate at the impact of the fragment at the initial velocity $\mathrm{v}=45 \mathrm{~m} / \mathrm{s}$ and the angle of impact: a) $0^{\circ}$, b) $15^{\circ}$, c) $30^{\circ}$ and d) $45^{\circ}$

a)
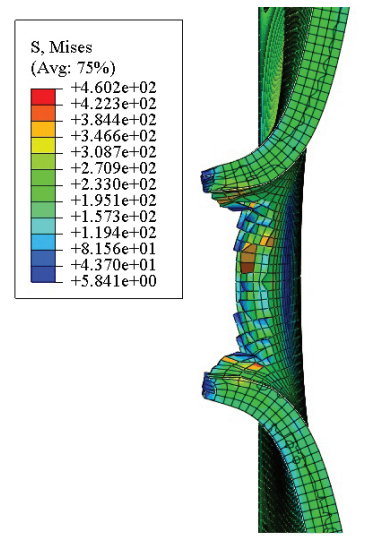

c)

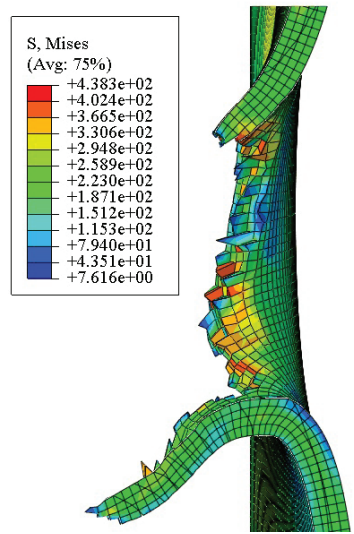

b)
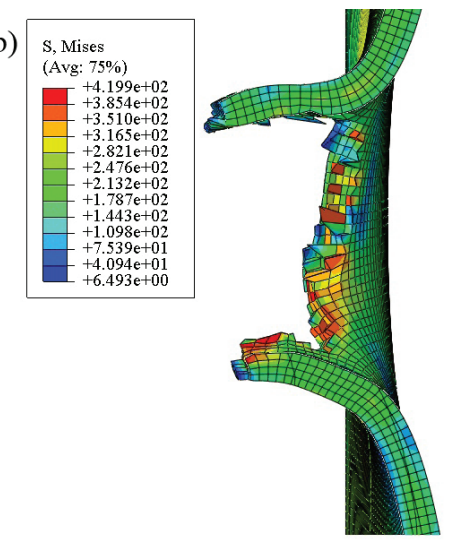

d)

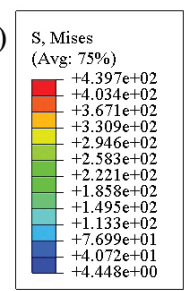

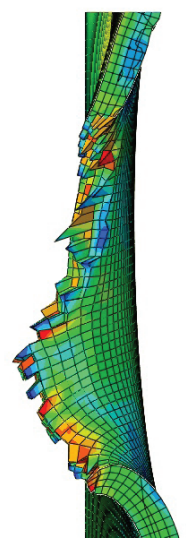

Fig. 6. Maps of reduced stresses in a ballistic plate at the impact of the fragment at the initial velocity $\mathrm{v}=55 \mathrm{~m} / \mathrm{s}$ and the angle of impact: a) $0^{\circ}$, b) $15^{\circ}$, c) $30^{\circ}$ and d) $45^{\circ}$ 
When the fragment impacted the plate at $35 \mathrm{~m} / \mathrm{s}$ at angles of $0^{\circ}$ and $15^{\circ}$, there was an over $80 \%$ drop in velocity compared to the initial velocity. This velocity was very similar to the reference velocity for the level of ballistic protection offered by a one-millimeter aluminum plate. However, for the impact angle of $30^{\circ}$, this velocity was close to $45 \mathrm{~m} / \mathrm{s}$, for which there was an $84.2 \%$ decrease in velocity (Fig. 7). Analogously, as the impact angle increased, so did the velocity of the fragment. It can also be seen that when this value was exceeded, there was a drastic decrease in velocity loss. This was directly related to the small thickness of the plate, which did not provide any real protection against the impact of the projectiles launched at higher velocities.

The numerical simulations discussed here modeled the actual contact between a penetrator and a target in which kinetic energy was lost. The kinetic energy of the penetrator was converted into work done by the fragment against the resistance of the aluminum plate. Additionally, as the plate was deformed upon impact, part of the kinetic energy was converted into permanent deformation work. It follows from the data shown in Fig. 8 that at the velocity of $35 \mathrm{~m} / \mathrm{s}$, there was an over $95 \%$ decrease in kinetic energy for the impact angles of $0^{\circ}$ and $15^{\circ}$. This is very close to plastic (inelastic) collision, in which $100 \%$ of kinetic energy is absorbed. A similar situation was observed for the projectile fired at the speed of $45 \mathrm{~m} / \mathrm{s}$ at the angle of $30^{\circ}$. For the fragments launched at the angle of $30^{\circ}$, an increase in velocity was accompanied by a greater loss of kinetic energy. However, this happened only until a certain velocity limit was reached, beyond which energy loss began to decrease. This was directly associated with the resistance force of the aluminum plate, where a large portion of the kinetic energy was initially converted into work to overcome the resistance force. At higher velocities, which were associated with an increase in kinetic energy, the work needed to overcome this force was negligibly low.

\section{DISCUSSION OF THE RESULTS}

The literature analysis limited to the problem of perforation of a thin-walled aluminum plate leads to the conclusion that it is difficult to compare the results of the research due to the

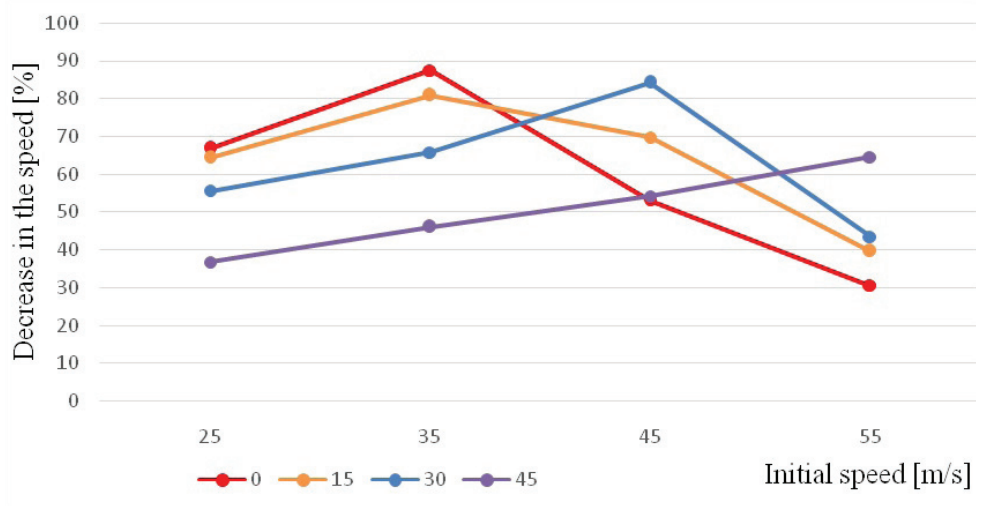

Fig. 7. Decrease in the speed of the fragment when hitting the ballistic panel depending on its initial velocity

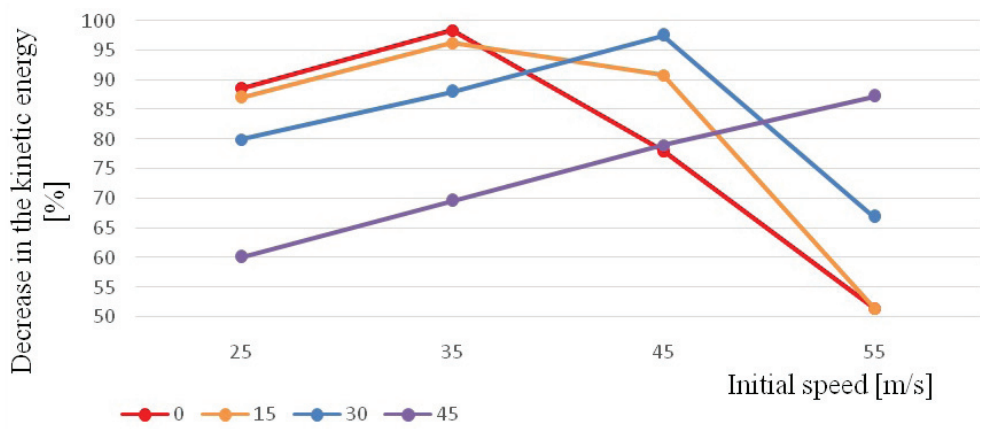

Fig. 8. Decrease in the kinetic energy of the fragment depending on the initial speed 
differences in the test objects. In the literature, there is no general direction of research on damage due to fragments, as in the case of ballistics related to projectiles. This is mainly due to the fact that the fragments radiating from one point hit the target from different directions and with different velocities. The impact is not always made with the frontal plane of the fragment. Two examples can be cited to confirm the very wide spectrum of research:

- In [2] reproduced the impact of a ricochet fragment. A titanium fragment with a diameter of $5.5 \mathrm{~mm}$ and a length of $127 \mathrm{~mm}$ impacted a plate with its side surface. At a velocity of $76.2 \mathrm{~m} / \mathrm{s}$ and incidence angle of $0^{\circ}$, it rebounded from the plate causing plastic deformation which, however, did not damage the structure.

- In $[3,9]$ the impact of a flat-nosed penetrator at a velocity of $42 \mathrm{~m} / \mathrm{s}, 45 \mathrm{~m} / \mathrm{s}$ and $54.2 \mathrm{~m} / \mathrm{s}$ resulted in the perforation of the plate. The results of numerical analysis were presented, where the penetration surface was similar to a circle and the circular fragment of the plate was completely torn away by the projectile. However, the results regarding the shape of the perforation were not confirmed by other authors.

The authors of this article conducted the simulation tests of the ballistic plate puncture based on the general guidelines presented in the standards $[17,18]$. The variables set during the simulation were the velocity of the fragment and the angle of its impact against the aluminum plate with a thickness of $1 \mathrm{~mm}$. A fragment moving at a velocity of $25 \mathrm{~m} / \mathrm{s}$ did not perforate the plate regardless of the angle of incidence; however, it did deform the target. When the velocity was too low for the penetrator to pass through the target, it ricocheted off the plate, losing some of its energy. Fired at an angle of $45^{\circ}$ the fragment always ricocheted off the target. The penetrator was the most effective when it was launched perpendicular to the target. By contrast, it was the most difficult for the fragment to penetrate the aluminum plate when it impacted the target at the angle of $45^{\circ}$. It can therefore be concluded that the level of ballistic protection will differ for varying impact angles. At the velocity of $35 \mathrm{~m} / \mathrm{s}$ and impact angles of $0^{\circ}$ and $15^{\circ}$ nearly $100 \%$ of kinetic energy is absorbed, which means the fragment comes into plastic collision with the target.

\section{CONCLUSIONS}

An analysis of stress distributions and energy dissipation allows determining the decrease in the velocity of a fragment simulating projectile which has impacted an aluminum plate as a function of the angle of incidence of a fragment. The kinetic energy of the whole system drops as the kinetic energy of the fragment is converted into permanent deformation work of the aluminum plate and work needed to overcome the resistance force. Due to the effectiveness of the ballistic panel, the most advantageous situation is when the panel remains intact despite the impact. According to the results of the simulations, the proposed panel is fully effective when the impact velocity of the fragment simulating projectile does not exceed $25 \mathrm{~m} / \mathrm{s}$. At the same time, it should be noted that increasing the angle of the expected impact is not a fully effective method of protection because it may lead to the ricochet of the fragment, the energy of which is not dissipated in contact with the panel. Such a case was observed in the simulation of an impact with a speed of $25 \mathrm{~m} / \mathrm{s}$ at an angle of $45^{\circ}$.

The tested plate does not fulfil its task as a ballistic shield for the impacts at higher velocities. Nevertheless, tests are planned to decide whether it would be advisable to increase the thickness of the plate, change the structure of the panel, or use a system of shields.

\section{REFERENCES}

1. Jena P. K., Savio S. G., Siva K. K., Madhu V., Mandal R.K. An experimental study on the deformation behaviour of aluminium armour plates impacted by two different non-deformable projectiles. Proccedia Engineering. 2017; 173: 222-229.

2. Damodar R., Navin J., Robin E. L., Norman F., Knight J. Numerical simulations for high-energy impact of thin plater. International Journal of Impact Engineering. 2001; 25: 683-702.

3. Iqbal M.A., Tiwari G., Gupta P.K., Bhargava P. Ballistic performance and energy absorption characteristics of thin aluminium plates. International Journal of Impact Engineering. 2015; 77: 1-15.

4. Jamroziak K. Identyfikacja własności materiałów w balistyce końcowej. Oficyna Wydawnicza Politechniki Wrocławskiej; 2013.

5. Senthil K., Iqbal M.A., Arindam B., Mittal R., Gupta N.K. Ballistic resistance of 2024 aluminium plates against hemispherical sphere and blunt nose projectiles. Thin-Walled Structures. 2018; 126: 94-105. 
6. Rodriguez-Millan M., Garcia-Gonzalez D., Rusinek A., Arias A. Perforation mechanics of 2024 aluminium protective plates subjected to impact by different nose shapes of projectiles. Thin-Walled Structures. 2018; 123: 1-10.

7. Gupta P., Iqbal M.A., Mohammad Z., Baqi A., Gupta N.K. Energy absorption in thin metallic targets subjected to oblique projectile impact. Procedia Engineering. 2017; 173: 145-152.

8. Zaid M., Pramod K., Abdul B. Experimental and numerical investigations on the behavior of thin metallic plate targets subjected to ballistic impact. International Journal of Impact Engineering. 2020; 14: 103-117.

9. Iqbal M.A., Tiwari G., Gupta P.K. Energy dissipation in thin metallic shells under projectile impact. European Journal of Mechanics A/Solids. 2016; 59: $37-57$.

10. Tiwari G., Iqbal M.A., Gupta P.K. Energy absorption characteristics of thin aluminium plate against hemispherical nosed projectile impact. Thin-Walled Structures. 2018; 126: 246-257.

11. Miller J. E., Bjorkman M. D., Christiansen E. L., Ryan S. J. Analytic ballistic performance model of whipple shields. Procedia Engineering. 2015; 103 : 89-397.

12. Mannan M.N., Ansari R., Abbas H. Failure of aluminum beams under low velocity impact. International Journal of Impact Engineering. 2008; 35: 1201-1212.

13. Bikakis G., Tsigkros N., Sideridis E. Ballistic impact response of 2024-T3 monolithic aluminum plates: prediction and comparison with GLARE 4A fiber-metal laminates. MATEC Web of Conferences 188, 02010 (2018) DOI:10.1051/matecconf/201818802010

14. Wróblewski A., Pracht M. Badania dynamiczne odłamków standardowych stosowanych do sprawdzeń osłon balistycznych. Wojskowy Instytut Techniczny Uzbrojenia. 2014; 5: 33-46.

15. Krzysiak Z., Samociuk W., Bartnik G., Plizga K., Dziki, D., Kaliniewicz Z., Nieoczym A., Wyciszkiewicz A. Analysis of tank safety with propane-butane on LPG distribution station. Polish Journal of Chemical Technology. 2017; 19 (4): 99-102.

16. Niezgoda T., Kosiuczenko K., Barnat W., Panowicz R. Symulacja numeryczna przebijania odłamkiem osłony balistycznej wykonanej z kompozytu. Modelowanie Inżynierskie. 2011; 42: 295-302.

17. PN-V-87001:2011. Osłony balistyczne lekkie. Hełmy kulo- i odłamkoodporne. Wymagania i badania.

18. PN-V-87000:2011.Osłony balistyczne lekkie. Kamizelki kulo- i odłamkoodporne. Wymagania i badania.

19. Janiszewski J., Panowicz R. Próba wyznaczenia wartości stałych równania Johnsona-Cooka na podstawie testu pierścieniowego. Biuletyn WAT. 2008; vol.57 (3): 25-43.

20. Zmindak M., Pelagić Z., Pastorek P., Mocilan M., Vybostok M. Finite element modelling of high velocity impact on plate structures. Procedia Engineering. 2016; 136: 162-168. 